\title{
Anadolu kestanesi (Castenia sativa Mill.) ağaç türünün CNC ile işlenmesinde yüzey pürüzlülüğünün işleme parametreleri ile ilişkisi
}

\author{
Oruç Aras ${ }^{1}$ (D), Sait Dündar Sofuoğlu ${ }^{2 *}$ (D)
}

$\ddot{\mathbf{O z}}$

$\mathrm{Bu}$ çalışmada, ağaç işleri ve mobilya endüstrisinde kullanılan Anadolu kestanesi (Castenia sativa Mill.) ağaç türüne ait numunelerin işlenmesinde işleme parametrelerinin yüzey kalitesi üzerine etkisi incelenerek optimum işleme koşullarının belirlenmesi amaçlanmıştır. Denemeler $8 \mathrm{~mm}$ çapında iki farklı kesici kullanılarak 8000, 12000 ve 16000 dev/dakika devir sayılarında 1000, 1500 ve $2000 \mathrm{~mm} /$ dak ilerleme hızlarında farklı iki işleme katman sayısında gerçekleştirilmiştir. Elde edilen yüzeylerde iğne taramalı yöntem kullanılarak TS 6956 EN ISO 4287' ye göre ortalama pürüzlülük $(R a)$ ölçümleri yapılmıştır. İşleme parametrelerinin yüzey kalitesi üzerinde farklı oranlarda etkisinin olduğu görülmüştür. Liflere dik yapılan ölçümlerde en düşük $R a$ değerleri 2 no'lu kesici tipinde, 16000 dev/dak devir sayısında, $1000 \mathrm{~mm} /$ dak ilerleme hızında ve 4 işleme katman sayısında elde edilmiştir. Liflere paralel yapılan ölçümlerde en düşük $R a$ değerleri 2 no'lu kesici tipinde, 12000 dev/dak devir sayısında, $2000 \mathrm{~mm} /$ dak ilerleme hızında ve 4 işleme katman sayısında elde edilmiştir.

Anahtar kelimeler: Ağaç malzeme, $\mathrm{CNC}$, işleme, kestane, yüzey pürüzlülüğü

\section{The relationship of machining parameters with surface roughness in machining of chestnut (Castenia sativa Mill.) tree species with CNC}

\begin{abstract}
In this study, the effect of machining parameters on the surface quality of the machining of the chestnut (Castenia sativa Mill.) tree species used in the woodworking and furniture industry was investigated, and it was aimed to determine the optimum machining parameters. The experiments were carried out at two different machining layers by using two different $8 \mathrm{~mm}$ diameter cutters at 8000, 12000 and $16000 \mathrm{rpm}$ at feed rates of 1000, 1500 and $2000 \mathrm{~mm} / \mathrm{min}$. Average roughness $(R a)$ measurements were made according to ISO 4287 by using a test device with the stylus method on the surfaces obtained in different sections. It has been observed that the machining parameters have an effect in different rates on the surface quality, and the results are evaluated by comparing with the literature. The lowest average roughness $(R a)$ value was obtained in 4-layer processing, $1000 \mathrm{~mm} / \mathrm{min}$ feed rate at $16000 \mathrm{rpm}$, cutter type 2 for measurements perpendicular to the fibers. The lowest average roughness $(R a)$ value was obtained in 4-layer processing, $2000 \mathrm{~mm} / \mathrm{min}$ feed rate at 12000 rpm, cutter type 2 for measurements parallel to the fibers.
\end{abstract}

Keywords: Wood, CNC, Machining, Chestnut, Surface roughness 


\section{Giriş}

Ahşap ve ahşap kökenli malzemelerin kullanıldığı ürünlerde yüksek kaliteli bir yüzey üretim sırasında ve sonrasında istenen bir özelliktir. Mobilya ve ağaç işleri sektöründe kaliteyi belirleyen unsurların en önemlilerinden birisi yüzey kalitesi olarak görülmektedir. Ahşap malzemenin yüzey kalitesini oluşturan önemli faktörlerden birisi de işleme tekniğidir (Stumbo, 1961). Türkiye mobilya endüstrisinde CNC makinelerin kullanımına 1990'l1 yıllarda başlanmıştır (Koç ve Koç, 2005). Günümüzde mobilya endüstrisinde kullanılan CNC tezgahlar müşteri isteklerine anında cevap verebilmekte, farklı tasarımların da uygulanmasına olanak sağlamaktadır. Düşük işçilik ücretleri ve yüksek kaliteli ürün imkanı ile diğer firmalara karşı rekabet üstünlüğü sağlamaktadır (Karagöz, 2010). Bunun sonucu olarak; Türkiye'de CNC tezgâhlara yapılan yatırımlar önemli derecede artış göstermiştir. Ancak aynı hassasiyet program seçiminde, takım seçiminde ve işleme parametresi seçiminde gösterilmemektedir (Karagöz 2011). İşleme esnasındaki uygulanacak bıçak adımı, bıçak motoru hızı, besleme hızı, kesme derinliği, işleme taktiği, bıçak dalma derinliği, dalma hızı gibi birçok ayarlamaları CNC makinelere kodlar vasıtası ile yüklenebilmektedir (Bal ve Akçakaya, 2018). Bu ayarlamalar işlenen yüzeyin yüzey pürüzlülüğünü değiştirebilmektedir. İşleme sonrası elde edilen yüzeyin kalitesi kullanılan ağaç malzemenin doğal tekstürüne ve işlemede kullanılan tekniğe bağlı olarak meydana gelmektedir (Marian ve Suchland, 1962). Her geçen gün azalan orman varlığı sebebiyle ağaç malzemenin; daha verimli işlenmesi, değerlendirilmesi ve daha uzun süre kullanılmak istenmesi gerek üreticiler gerekse kullanıcılar açısından istenen bir özellik olmuştur (Sofuoğlu, 2008). Ağaç malzemenin işlenme aşamalarının birinde düzgün olmayan yüzeylerin meydana gelmesi, bir sonraki üretim aşamasında zımparalama gibi ek işlemlere ihtiyaç duyulmasına neden olmaktadır. Ahşap ürünlerdeki yüzey kalitesi son kullanıcının kalite kriterleri içerisinde bulunmaktadır (Aykaç, 2018). Ahşap malzemeler genellikle yüzey düzgünlüğünün önemli olduğu benzer malzemelere göre daha yüksek pürüzlülük değerleri vermektedir. Ağaç malzeme uygun alet, kesici ve makinelerle işlenmelidir. İşleme şekli ve ağacın yaşıyla orantılı olarak; yüzeylerde kesici izlerinin düzenli şekilleri ile beraber istenmeyen bozuk yüzeyler meydana gelebilmektedir. Ağaç malzemenin birleştirilmesinde, birleştirme yerlerinde ve yüzeylerdeki yapışma gücü, yüzey pürüzlülügü ile ilişkili olabilmektedir. Pürüzsüz ahşap kaplamalardaki yapışma kalitesi pürüzlü olanlara göre daha yüksektir. Yüzey pürüzlülüğü üst yüzey işlemlerinin kalitesini de etkilemektedir (Jakub ve Martino, 2005). Ağaç malzemede kaliteli ve düzgün yüzeyler elde etmek için işlenme özelliklerinin bilinmesi, uygulanması önemlidir (Sofuoğlu, 2008). Genel bir kural olarak, işlem gören iş parçasının yoğunluğu arttıkça (demir, çelik vs.) besleme hızı, bıçak adımı ve kesme derinliği küçük tutulmak zorundadır. Ahşap malzemeler gibi yoğunluğu düşük ve işlenmesi kolay malzemelerde ise bu ayarlar büyük tutulmaktadır ve malzeme yoğunluğuna göre bu ayarlamalar değişmektedir (Bal, 2018). Ahşap ve ahşap kökenli malzemelerin işlenmesinde yüzey kalitesi her açıdan önemlidir. Ahşap ve ahşap kökenli malzemelerin (çoğunlukla MDF) çeşitli işleme parametrelerinin değiştirilerek CNC ile işlenmesinde yüzey kalitesinin belirlenmesine yönelik literatürde çalışmalar bulunmaktadır (Karagöz, 2010; Sütcü ve Karagöz, 2012; Kacal ve Sofuoglu, 2013; Sofuoglu ve Kaçal, 2013; Sofuoglu, 2015a; Sofuoglu, 2015b; Sofuoglu, 2016; Koç ve ark., 2017; Bal, 2018; İşleyen ve Karamanoğlu, 2019). Optimum noktanın belirlenmesinde heterojen yapısından dolayı her ağaç türünde farklı sonuçlar ortaya çıkabilmektedir.

$\mathrm{Bu}$ çalışmada ise Anadolu kestanesi ağaç türünün $\mathrm{CNC}$ ile işlenmesinde, işleme parametrelerinin yüzey pürüzlülüğü ile ilişkisinin araştırılması hedeflenmiş ve pürüzsüz yüzey elde edebilmek için optimum koşulların belirlenmesi amaçlanmıştır. 


\section{Materyal ve Metot}

\subsection{Materyal}

Çalışmada deneme materyali olarak Anadolu kestanesi (Castenia sativa Mill.) ağaç türü kullanılmıştır. Anadolu kestanesi Türkiye'de doğal yayılış göstermektedir. Kurutulması güçtür, çatlama ve dönüklüğe eğilimlidir. İşlenmesi kolaydır, güç yarılır. Çivileme ve vida tutması iyidir. Kolay cilalanır. (Bozkurt, 1992; Bozkurt ve Erdin, 1997; Bozkurt ve Erdin, 2000).

Denemelerde kullanılan ağaç malzeme Kütahya, Simav'daki kereste fabrikasından rastgele seçim yoluyla elde edilmiştir. Denemelerde kullanılan Anadolu kestanesinin hava kurusu yoğunluğu $0,56 \mathrm{gr} / \mathrm{cm}^{3}$ olarak tespit edilmiştir.

Numunelerin işlenmesinde Kütahya Dumlupınar Üniversitesi Simav Teknoloji Fakültesi Ağaç İşleri Endüstri Mühendisliği Bölümü’nde bulunan SKILLED 2040 üç eksen CNC dik işleme makinesinden yararlanılmıştır. Şekil 1'de çalışmada kullanılan CNC tezgahı verilmektedir.

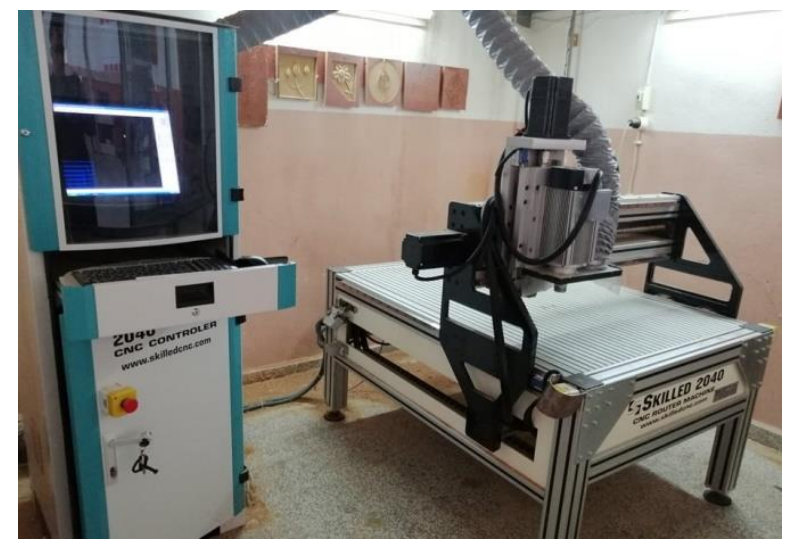

Şekil 1. Skilled CNC 2040 üç eksen CNC dik işleme tezgahı (Aras, 2019)

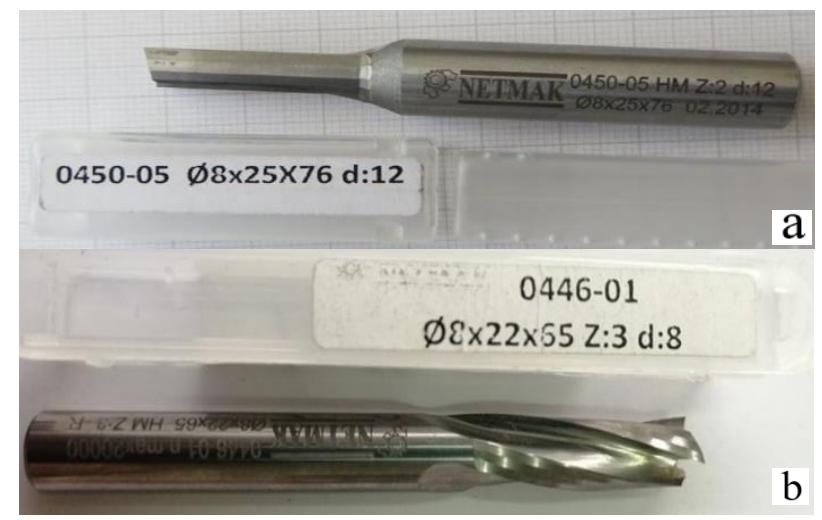

Şekil 2. İki ağızlı düz parmak freze (a), Üç ağızlı spiral hassas kesim bıçağı (b)

Kesici tipi olarak, Netmak isimli firmadan temin edilen, yüksek hız çeliği (HSS)'nden üretilmiş $8 \mathrm{~mm}$ çapında farklı kesici kenar sayısına sahip $(Z=2, Z=3)$ düz parmak frezeler kullanılmıştır (Şekil 2). Çevrelerinde ve uç yüzeylerinde iki veya daha fazla kesici ağızları bulunmaktadır. Pürüzlülük ölçümlerinde ardışık profil değişimini ölçebilen Time TR-200 dokunmalı (iğneli) yüzey pürüzlülük ölçüm cihazı kullanılmıştır. 


\subsection{Metot}

Rastgele seçim metodu ile elde edilen keresteler oda koşullarında 6 ay süre ile doğal kurutmaya bırakılmıştır. Daha sonra yaklaşık 55x6x2 cm ölçülerine getirilmiştir. Sonrasında denemeler için hazırlanan bu numuneler sabit ağırlığa gelinceye kadar (üç hafta süre ile) $20 \pm$ $2{ }^{\circ} \mathrm{C}$ sicaklık ve $\% 65 \pm 5$ nisbi rutubette klimatize dolabında bekletilerek rutubet miktarının $\% 12 \pm 2$ 'ye gelmesi sağlanmıştır. ArtCAM yazılımı kullanılarak uzun kenarları $5 \mathrm{~cm}$ kısa kenarları $2 \mathrm{~cm}$ ebatlarında, $10 \mathrm{~mm}$ işleme derinliğinde L şeklinde zigzag takım yolu ile işleme gerçekleştirilmiştir (Şekil 3). Deney tasarımının oluşturulmasında belirlenen işleme parametreleri ve düzeyleri Çizelge 1 'de verilmektedir.

Çizelge 1. İşleme parametreleri, düzeyleri ve değerleri (Aras, 2019)

\begin{tabular}{|c|c|}
\hline İsleme parametreleri & Düzevler ve değerler \\
\hline Katman sayısı & 3,4 \\
\hline Devir sayısı (dev/dak) & $8000,12000,16000$ \\
\hline İlerleme hızı (mm/dak) & $1000,1500,2000$ \\
\hline Kesici tipi & 1,2 \\
\hline
\end{tabular}
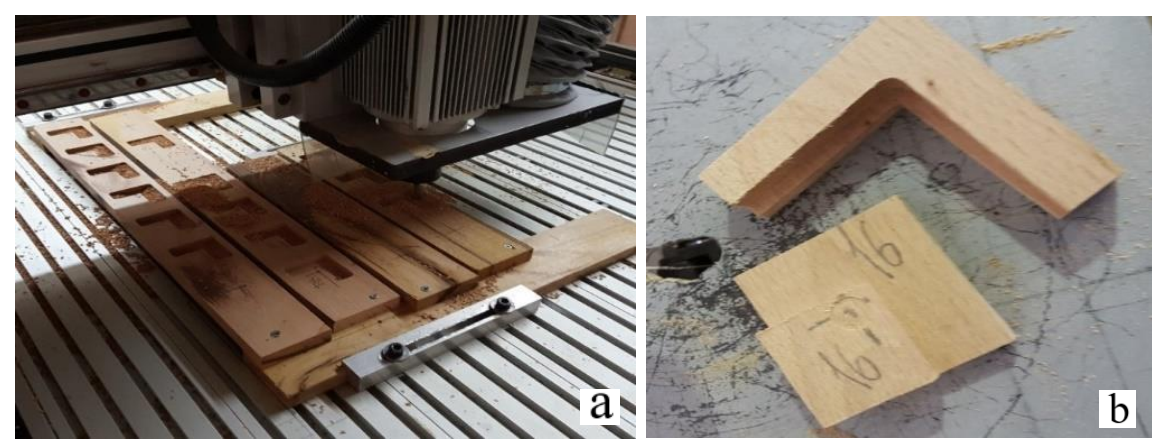

Şekil 3. a. CNC ile deney numunelerinin işlenmesi b. Numuneleri kesilerek pürüzlülük ölçümü için uygun hale getirilmesi

Ortalama pürüzlülük parametresi, yüzey pürüzlülüğü ölçümlerinde en yaygın kullanılan parametredir (Aydın ve Çolakoğlu, 2003). Bu kapsamda bu çalışmada ortalama pürüzlülük parametresi kullanılmış ve değerlerinin elde edilmesinde TS EN 6956 EN ISO 4287 standardı kullanılmıştır. Ölçümler; numunelerin zemin yüzeylerinde liflere dik ve liflere paralel şekilde gerçekleştirilmiştir (Şekil 4). Ölçme adımı (cut-off) $0,8 \mathrm{~mm}$ alınıp, yüzey pürüzlülük değerleri belirlenecek numuneler ve cihaz yere paralel olacak şekilde yerleştirilip 5'er tekrar ile ölçme işlemleri gerçekleştirilmiştir. Ölçüm sürecinde cihazın kalibrasyonu belli aralıklarla kontrol edilmiştir.

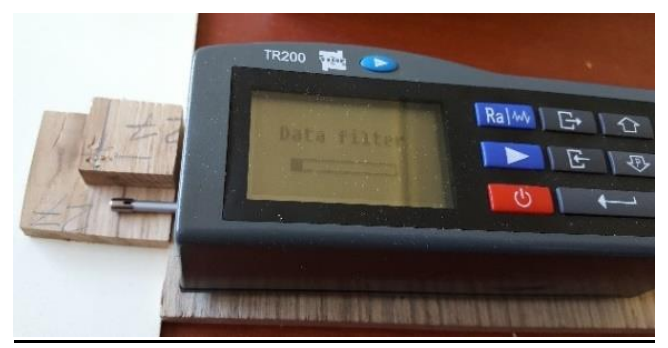

Şekil 4. Zemin yüzeylerde pürüzlülük değerlerinin belirlenmesi 


\section{3. İstatistiksel Analiz}

Elde edilen veriler üzerinde Minitab 19 yazılımı kullanılarak, \%95 güven düzeyinde normallik testi gerçekleştirilmiştir. Verilere, varyans analizi (ANOVA) uygulanmış ve faktörler arası etkileşim grafiğgi çizilerek değerlendirmeler yapılmıştır. Sonuçlar tablo ve grafikler halinde verilmiştir.

\section{Bulgular ve Tartışma}

İşlenen zemin yüzeylerde $R a$ üzerine kesici tipinin, devir sayısının, ilerleme hızının ve işleme katman sayısının etkisini belirlemek amacıyla liflere dik ve paralel pürüzlülük ölçümleri gerçekleştirilmiş ve istatistiksel metotlar kullanılarak değerlendirilmiştir. Çizelge 2 'de elde edilen $R a$ değerleri verilmektedir.

Çizelge 2. Zemin yüzeylerde liflere dik ve paralel yapılan ölçümlerde elde edilen ortalama pürüzlülük $(R a)$ değerleri (Aras, 2019)

\begin{tabular}{|c|c|c|c|c|c|}
\hline \multirow[b]{2}{*}{ Kesici tipi } & \multirow{2}{*}{$\begin{array}{c}\text { Devir sayısı } \\
\text { (dev/dak) }\end{array}$} & \multirow{2}{*}{$\begin{array}{c}\text { İlerleme hızı } \\
\text { (mm/dak) }\end{array}$} & \multirow{2}{*}{$\begin{array}{l}\text { İşleme } \\
\text { katman } \\
\text { sayısı }\end{array}$} & \multicolumn{2}{|c|}{$R a(\mu \mathrm{m})$} \\
\hline & & & & Liflere dik & Liflere paralel \\
\hline 1 & 8000 & 1000 & 3 & 5.54 & 3.99 \\
\hline 1 & 8000 & 1000 & 4 & 5.16 & 2.49 \\
\hline 1 & 8000 & 1500 & 3 & 6.51 & 2.64 \\
\hline 1 & 8000 & 1500 & 4 & 5.40 & 4.96 \\
\hline 1 & 8000 & 2000 & 3 & 3.56 & 3.67 \\
\hline 1 & 8000 & 2000 & 4 & 5.22 & 2.69 \\
\hline 1 & 12000 & 1000 & 3 & 4.94 & 2.21 \\
\hline 1 & 12000 & 1000 & 4 & 5.72 & 3.65 \\
\hline 1 & 12000 & 1500 & 3 & 6.26 & 2.87 \\
\hline 1 & 12000 & 1500 & 4 & 6.29 & 1.70 \\
\hline 1 & 12000 & 2000 & 3 & 6.60 & 4.81 \\
\hline 1 & 12000 & 2000 & 4 & 4.59 & 2.54 \\
\hline 1 & 16000 & 1000 & 3 & 4.55 & 2.59 \\
\hline 1 & 16000 & 1000 & 4 & 4.48 & 4.91 \\
\hline 1 & 16000 & 1500 & 3 & 5.79 & 4.11 \\
\hline 1 & 16000 & 1500 & 4 & 5.17 & 3.72 \\
\hline 1 & 16000 & 2000 & 3 & 5.19 & 3.51 \\
\hline 1 & 16000 & 2000 & 4 & 6.76 & 3.42 \\
\hline 2 & 8000 & 1000 & 3 & 5.58 & 4.13 \\
\hline 2 & 8000 & 1000 & 4 & 5.20 & 4.48 \\
\hline 2 & 8000 & 1500 & 3 & 6.32 & 3.55 \\
\hline 2 & 8000 & 1500 & 4 & 5.42 & 3.59 \\
\hline 2 & 8000 & 2000 & 3 & 5.48 & 2.73 \\
\hline 2 & 8000 & 2000 & 4 & 4.18 & 2.40 \\
\hline 2 & 12000 & 1000 & 3 & 5.13 & 3.47 \\
\hline 2 & 12000 & 1000 & 4 & 4.33 & 2.26 \\
\hline 2 & 12000 & 1500 & 3 & 6.10 & 3.50 \\
\hline 2 & 12000 & 1500 & 4 & 5.69 & 3.99 \\
\hline 2 & 12000 & 2000 & 3 & 4.02 & 2.64 \\
\hline 2 & 12000 & 2000 & 4 & 5.06 & 3.13 \\
\hline 2 & 16000 & 1000 & 3 & 3.65 & 3.55 \\
\hline 2 & 16000 & 1000 & 4 & 4.29 & 1.99 \\
\hline 2 & 16000 & 1500 & 3 & 6.80 & 4.19 \\
\hline 2 & 16000 & 1500 & 4 & 3.56 & 2.43 \\
\hline 2 & 16000 & 2000 & 3 & 3.52 & 4.47 \\
\hline 2 & 16000 & 2000 & 4 & 4.72 & 1.85 \\
\hline
\end{tabular}


Şekil 5'de liflere dik yapılan ölçümlerde elde edilen $R a$ değerleri üzerine normallik testi yapılmış ve elde edilen grafik ve sonuçlar verilmiştir.

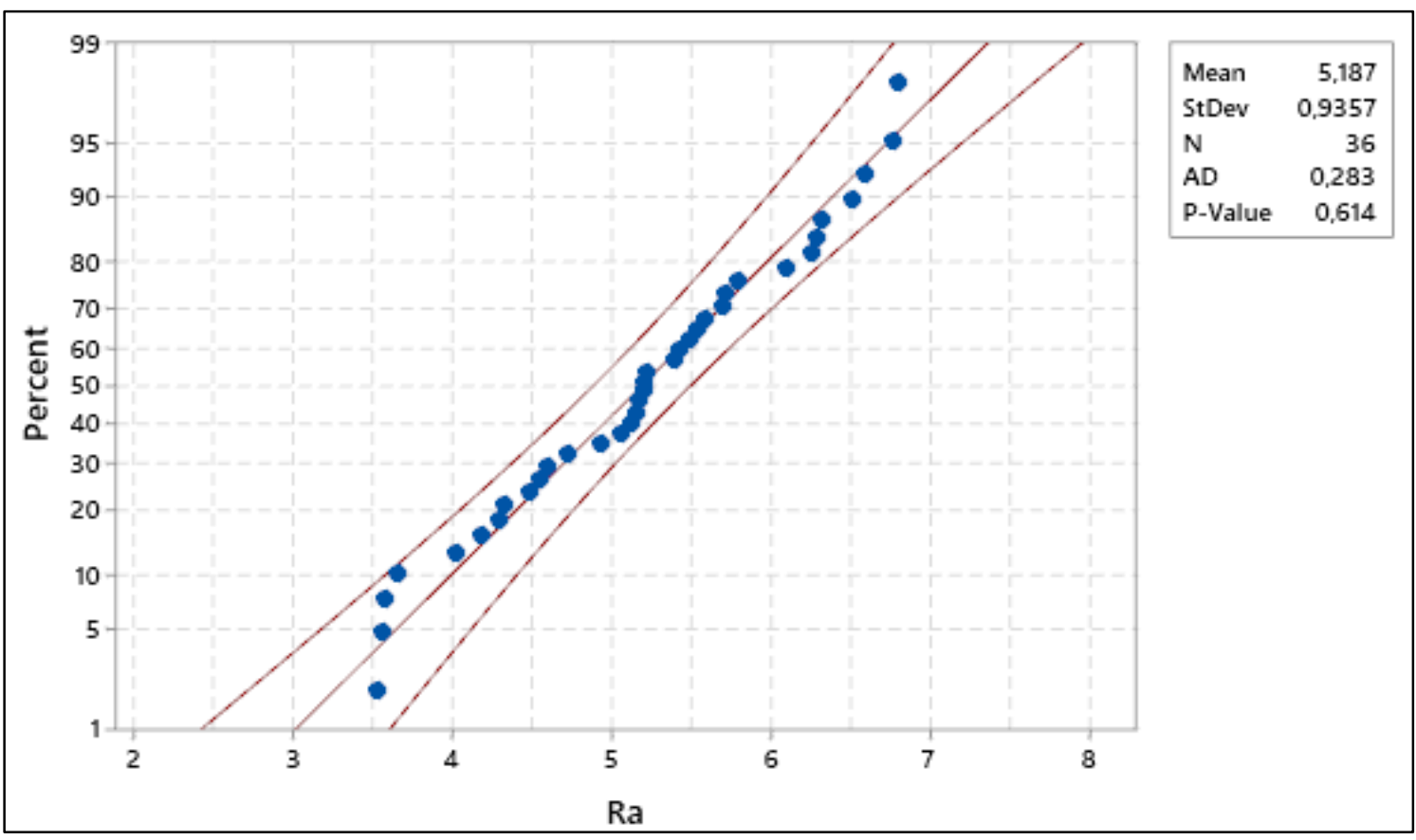

Şekil 5. Liflere dik yapılan ölçümlerde ortalama pürüzlülük $\left(R_{a}\right)$ için normallik grafiği.

Şekil 5'e göre $P$ değeri 0,05 'ten büyük $(P=0,614)$ elde edildiğinden, $R a$ ölçümünde değerlerin \%95 güven düzeyinde normal dağılım gösterdiği görülmektedir.

Zemin yüzeyde liflere dik yapılan ölçümlerde $R a$ için varyans analizi sonuçları Çizelge 3'de verilmektedir.

Çizelge 3. Liflere dik yapılan ölçümlerde $R a$ için varyans analizi sonuçları.

\begin{tabular}{|l|c|c|c|c|c|}
\hline \multirow{2}{*}{\multicolumn{1}{|c|}{ Kaynak }} & \multirow{2}{*}{$\begin{array}{c}\text { Serbestlik } \\
\text { derecesi }\end{array}$} & $\begin{array}{c}\text { Kareler } \\
\text { toplami }\end{array}$ & $\begin{array}{c}\text { Ortalama } \\
\text { kareler }\end{array}$ & $\mathbf{F}$ & $\mathbf{P}$ \\
\hline Kesici tipi & 1 & 2.0948 & 2.0948 & 3.05 & 0.092 \\
\hline Devir sayıs1 (dev/dak) & 2 & 1.8315 & 0.9158 & 1.33 & 0.280 \\
\hline İlerleme hızı (mm/dak) & 2 & 6.2519 & 3.1259 & 4.54 & 0.019 \\
\hline İşleme katman sayıs1 & 1 & 0.5148 & 0.5148 & 0.75 & 0.394 \\
\hline Hata & 29 & 19.9494 & 0.6879 & & \\
\hline Toplam & 35 & 30.6424 & & & \\
\hline
\end{tabular}

Çizelge 3'e göre \%95 güven düzeyindeki varyans analiz sonuçlarına göre $R a$ için ilerleme hızı için $p=0,019<0,05$, olduğundan istatistiksel olarak anlamlı bir fark bulunmaktadır. Diğer tüm faktörler için $P>0,05$ olduğundan anlamlı bir fark bulunmamaktadır. Şekil 6'de ise zemin yüzeyde liflere dik yapılan ölçümlerde $R a$ için ana etki grafiğgi verilmektedir. 


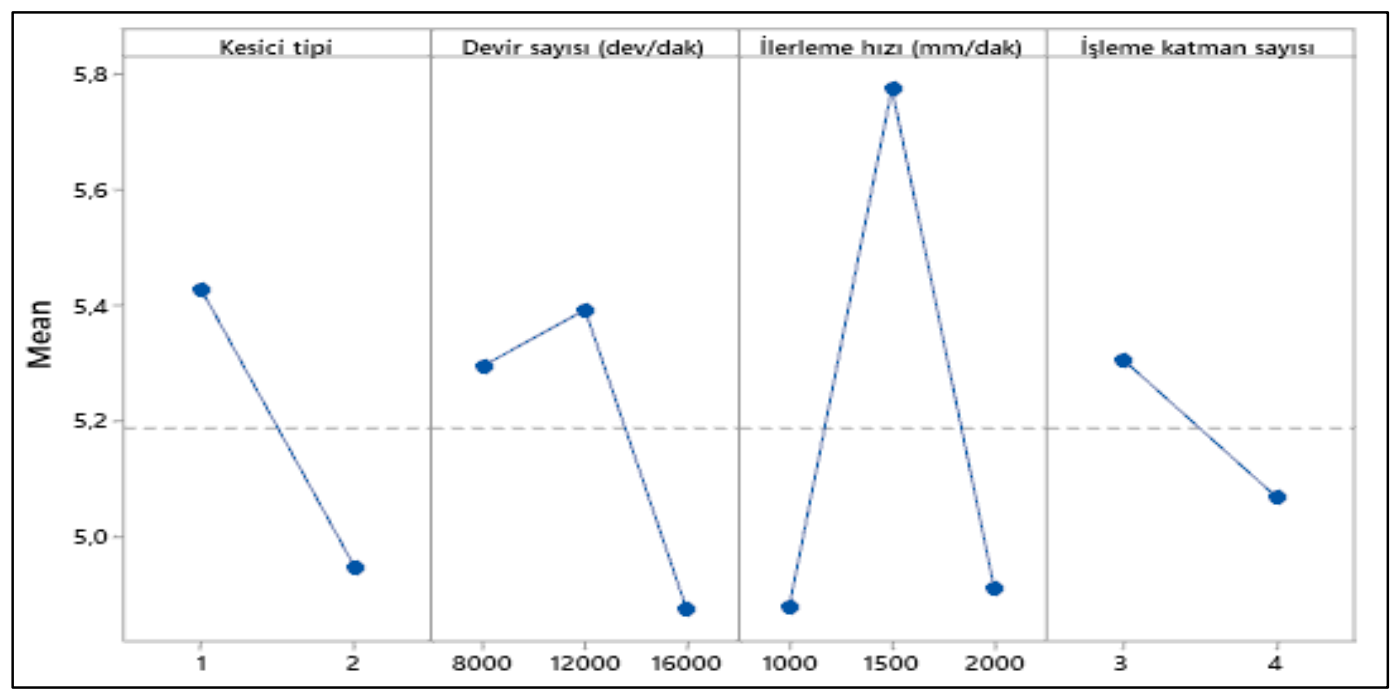

Şekil 6. Zemin yüzeyde liflere dik yapılan ölçümlerde kesici tipi, devir sayısı, ilerleme hızı ve işleme katman sayısının $R a$ üzerine etkisi.

Şekil 6'daki ana etki grafiğine göre zemin yüzeyde liflere dik yapılan ölçümlerde; 2 no'lu kesici ile işlenen yüzeylerde daha düşük $R a$ değerleri elde edilmiştir. Devir sayısı 8000 dev/dak'dan 12000 dev/dak'ya yükseltildiğinde pürüzlülük değerinde az da olsa artış meydana gelmiştir. $16000 \mathrm{dev} /$ dak'ya arttırıldığında ise $R a$ değerinde düşüş meydana gelmiş ve en düşük pürüzlülük değeri bu devir sayısında elde edilmiştir. $1000 \mathrm{~mm} /$ dak ilerleme hızında en düşük pürüzlülük değeri elde edilirken, ilerleme hızının 1500'e çıkması ile pürüzlülük değerinde artış meydana gelmiş ve en yüksek pürüzlülük değeri $1500 \mathrm{~mm} / \mathrm{dak}$ 'da meydana gelmiştir. İlerleme hızı $2000 \mathrm{~mm}$ /dak'ya çıkarıldığında ise yüzey pürüzlülük değeri tekrardan düşmüş ve $1000 \mathrm{~mm} /$ dak da elde edilen değere yakın bir $R a$ değeri elde edilmiștir. En düşük $R a$ değerleri 2 no'lu kesici tipinde, 16000 dev/dak devir sayısında, $1000 \mathrm{~mm} / \mathrm{dak}$ ilerleme hızında ve 4 işleme katman sayısında elde edilmiştir.

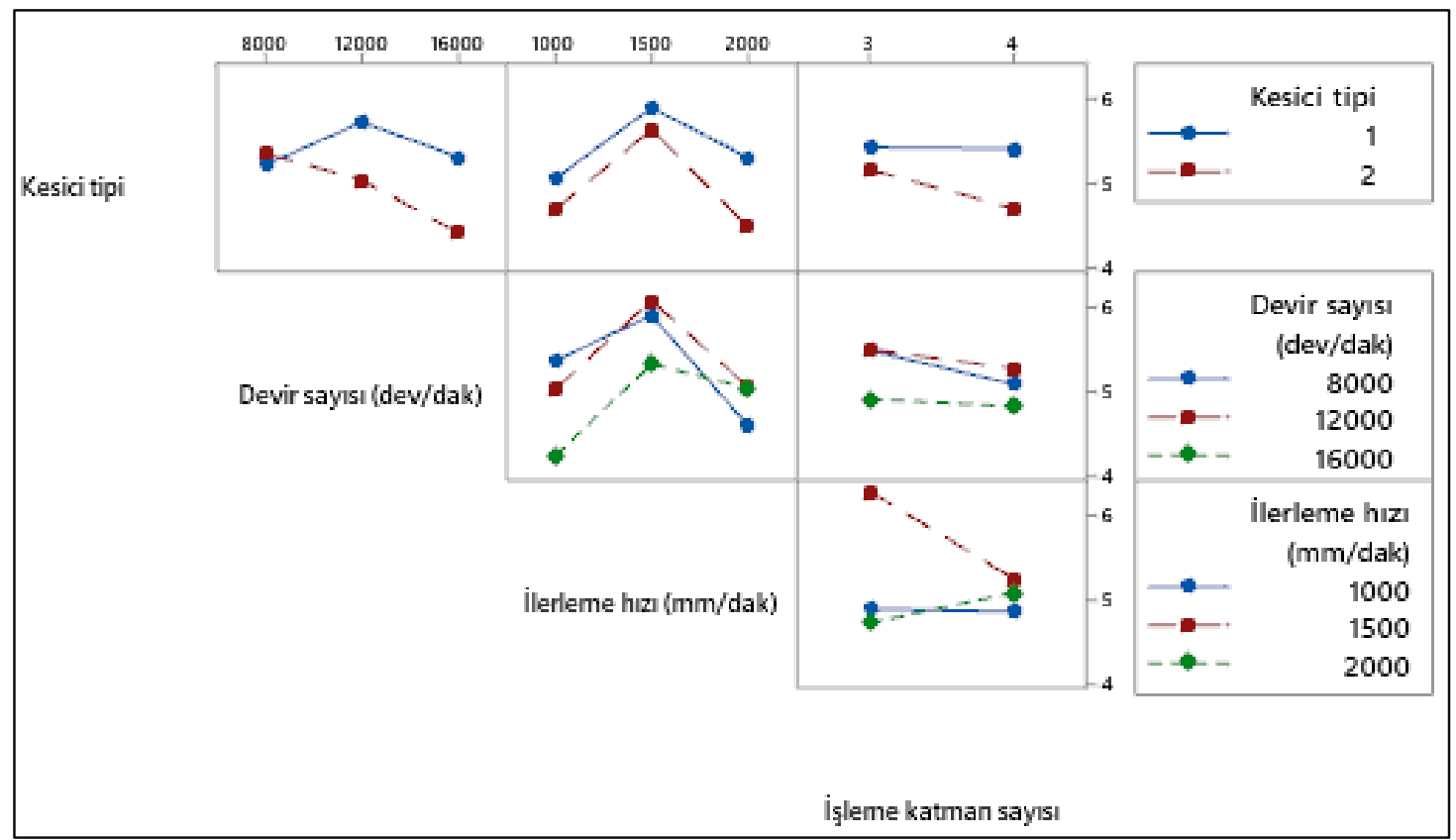

Şekil 7. Liflere dik yapılan ölçümlerde işleme faktörlerinin $R a$ açısından etkileşimleri 
Etkileşim grafiği değerlendirildiğinde 1 nolu kesicinin her iki işleme katman sayısında birbirine yakın $R a$ değerleri verdiği, 2 no'lu kesicinin ise 4 işleme katman sayısında daha düşük $R a$ değeri verdiği görülmüsşür. Bütün devir sayılarında 4 işleme katman sayısında en düşük $R a$ değerleri elde edilmiştir. Her üç ilerleme hızında işleme katman sayısında 4 katman sayısında birbirine yakın değerler elde edilmiştir. Her iki kesicide de ve her devir sayısında $1500 \mathrm{~mm} /$ dak ilerleme hızında en yüksek $R a$ değerleri elde edilmiştir. 2 nolu kesici her iki işleme katman sayısında, her ilerleme hızında ve her devir sayısında daha düşük $R a$ değerleri vermiş, ancak $8000 \mathrm{dev} / \mathrm{dak}$ 'da birbirine yakın değerler elde edilmiştir.

Liflere paralel yapılan yüzey pürüzlülük ölçümlerinde elde edilen $R_{a}$ değerleri normallik testine tabi tutulmuştur (Şekil 8).

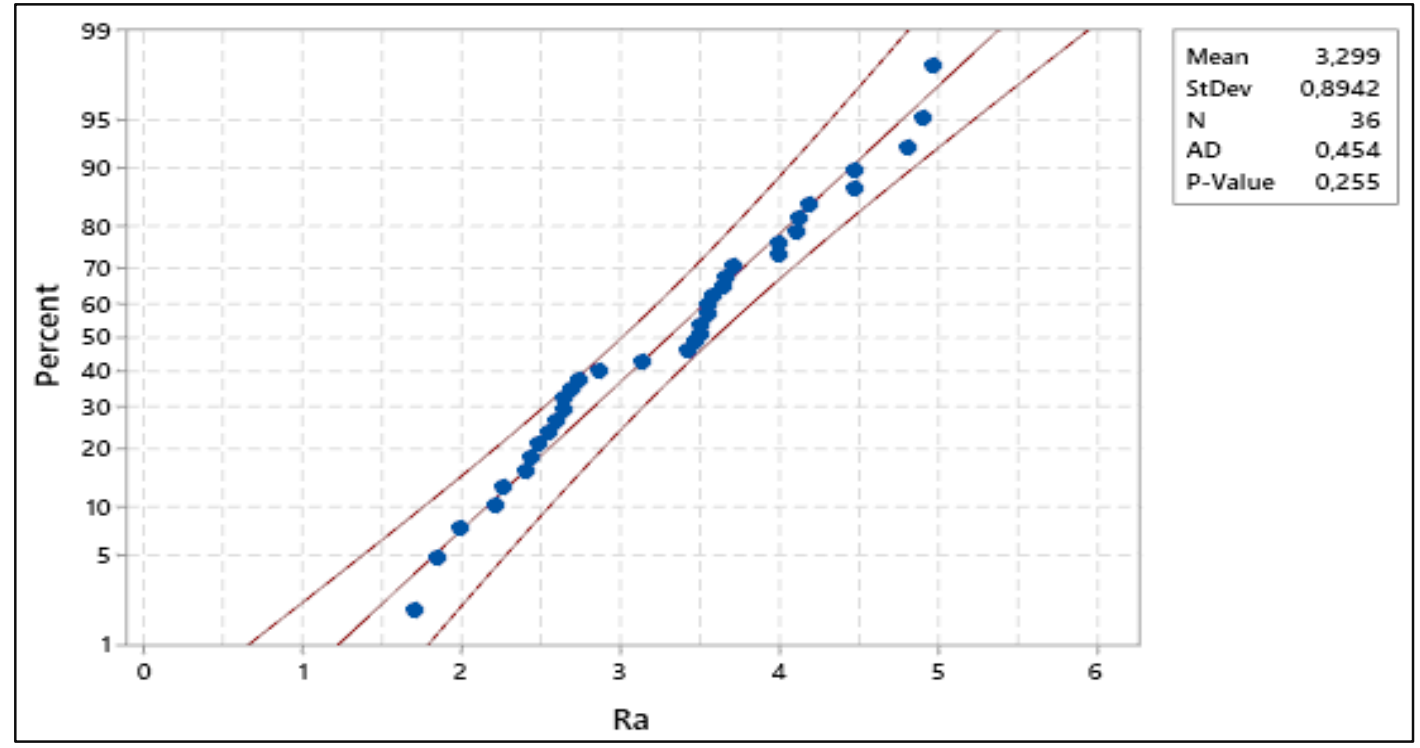

Şekil 8. Liflere paralel yapılan ölçümlerde $R_{a}$ için normallik grafiği

Normallik grafiğine göre $P=0,255>0,05$ elde edildiğinden ortalama pürüzlülük ölçümünde elde edilen ortalama $R a$ değerlerinin $\% 95$ güven düzeyinde normal dağ 11 ım gösterdiği görülmektedir.

Zemin yüzeyde liflere paralel yapılan ölçümlerde yüzey pürüzlülük parametreleri için varyans analizi sonuçları Çizelge 4'de verilmektedir.

Çizelge 4. Liflere paralel yapılan ölçümlerde $R a$ için varyans analizi sonuçları

\begin{tabular}{|c|c|c|c|c|c|}
\hline \multirow[b]{2}{*}{ Kaynak } & \multirow{2}{*}{$\begin{array}{l}\text { Serbestlik } \\
\text { derecesi }\end{array}$} & \multicolumn{4}{|c|}{$R a$} \\
\hline & & $\begin{array}{l}\text { Kareler } \\
\text { toplamı }\end{array}$ & $\begin{array}{c}\text { Ortalama } \\
\text { kareler }\end{array}$ & $\mathbf{F}$ & $\mathbf{P}$ \\
\hline Kesici tipi & 1 & 0.1232 & 0.1232 & 0.14 & 0.709 \\
\hline Devir sayısı (dev/dak) & 2 & 1.0207 & 0.5104 & 0.59 & 0.562 \\
\hline İlerleme hızı (mm/dak) & 2 & 0.4827 & 0.2413 & 0.28 & 0.760 \\
\hline İşleme katman sayısı & 1 & 1.1421 & 1.1421 & 1.31 & 0.261 \\
\hline Hata & 29 & 25.2153 & 0.8695 & & \\
\hline Toplam & 35 & 27.9840 & & & \\
\hline
\end{tabular}

Çizelge 4'e göre \%95 güven düzeyinde $R a$ için yapılan varyans analiz sonuçlarına göre tüm faktörlerde $\mathrm{p}>0,05$ olduğundan anlamlı bir fark bulunmamaktadır. Şekil 9'da ise zemin yüzeyde liflere paralel yapılan ölçümlerde $R a$ için ana etki grafiği görülmektedir. 


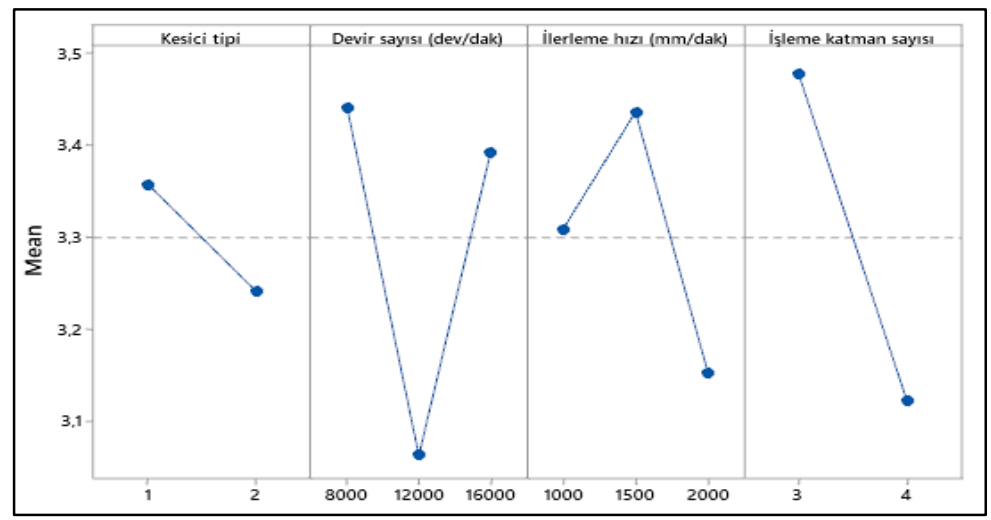

Şekil 9. Zemin yüzeyde liflere paralel yapılan ölçümlerde kesici tipi, devir sayısı, ilerleme hızı ve işleme katman sayısının $R a$ üzerine etkisi.

Şekil 9'daki liflere paralel yapılan ölçümlerde $R a$ için ana etki grafiği incelendiğinde; 2 no'lu kesici ile işlenen yüzeylerde daha düzgün yüzeyler elde edilmiştir. Devir sayısı 8000 dev/dak'dan 12000 dev/dak'ya yükseltildiğinde pürüzlülük değerinde düşme meydana gelmiştir. 16000 dev/dak'ya arttırıldığında ise $R a$ değerinde tekrardan artış meydana gelmiş ve en düşük Ra değeri 12000 dev/dak'da elde edilmiştir. İlerleme hızının 1000 mm/dak'dan 1500'e çıkartılması ile pürüzlülük değerinde artış meydana gelmiş, $2000 \mathrm{~mm} / \mathrm{dak}$ 'ya yükseltilmesi ile en düşük $R a$ değeri elde edilmiştir. En düşük $R a$ değerleri 2 no'lu kesici tipinde, $12000 \mathrm{dev} /$ dak devir sayısında, $2000 \mathrm{~mm} /$ dak ilerleme hızında ve 4 işleme katman sayısında elde edilmiştir.

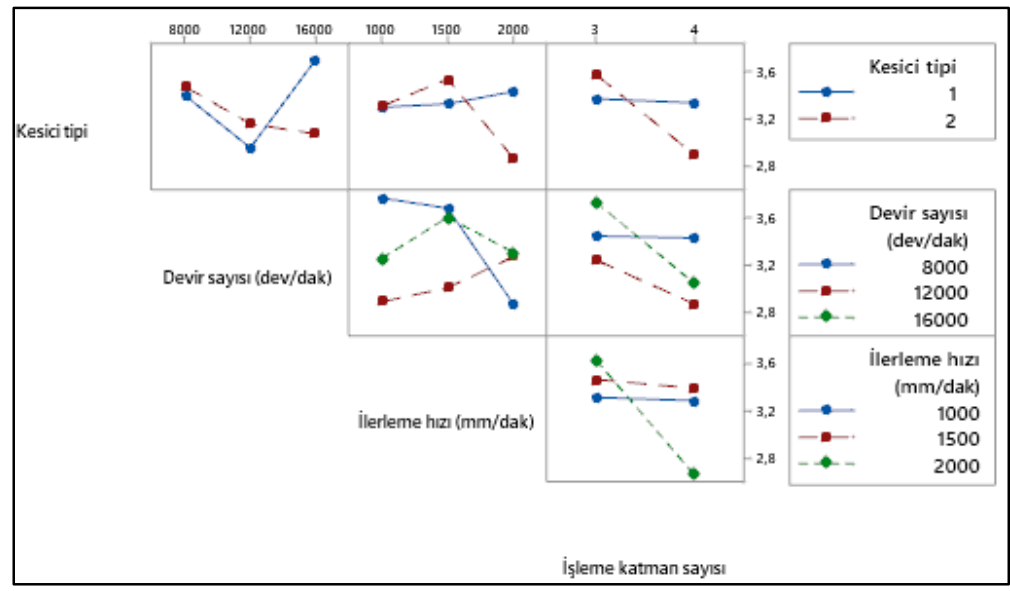

Şekil 10. Liflere paralel yapılan ölçümlerde işleme faktörlerinin $R a$ açısından etkileşimleri.

Şekil 10'a göre liflere paralel yapılan ölçümlerde etkileşim grafiği genel olarak değerlendirildiğinde bazı durumlarda birbirine yakın değerler elde edilmiş olsa da genel olarak 2 no'lu kesici tipinde daha düşük pürüzlülük değerleri elde edildiği söylenebilir. Liflere dik ölçümlerdekine benzer şekilde liflere paralel ölçümlerde de 8000 dev/dak'da 1 ve 2 nolu kesici birbirine yakın $R a$ değeri vermiştir.

Dönerek işleyen kesicilerde devir sayısının arttırılması ile birlikte pürüzlülük değerlerinde düşme meydana gelmekte ve daha düzgün yüzeyler elde edilebilmektedir (Davim, vd., 2009; Karagöz, 2010; Sütçü ve Karagöz, 2012; Sofuoğlu, 2015a; Sofuoğlu, 2015b; Koç, vd., 2017; Hazır, vd., 2018; Aykaç ve Sofuoğlu, 2021; Tosun, 2021). Genel olarak değerlendirildiğinde çalışmada elde edilen değerlerin literatür ile benzer eğilimler gösterdiği görülmektedir. Bazı durumlarda meydana gelen farklılıkların ağaç malzemenin 
heterojen yapıya sahip olması dolayısı ile anatomik yapısından kaynaklanabileceği düşünülebilir. Kesicilerin malzeme yüzeyinde birim mesafedeki kesici izi sayısı ne kadar yüksekse o kadar düzgün yüzeyler elde edilebilmektedir (Malkoçoğlu ve Özdemir, 2006; Sofuoğlu, 2008; Sofuoğlu ve Kurtoğlu, 2014, Efe vd., 2003; Usta vd., 2007; Tiryaki, 2014; Tiryaki vd., 2014). Bu durum 2 nolu kesicinin 3 ağızlı olması, yan yüzeylerinin helisel, eğimli kesici kenarlara sahip olması, zemin yüzeylerin işlenmesinde daha düzgün yüzeyler elde edilmesini sağlamış ve literatüre benzer sonuçlar elde edilmiştir.

\section{Sonuçlar ve Öneriler}

$\mathrm{Bu}$ çalışmada, Anadolu kestanesi (Castenia sativa Mill.) ağaç türünden hazırlanan numunelerin optimum işleme koşullarını belirlemek amacıyla, CNC makinesinde çeşitli parametreler değiştirilerek işleme gerçekleştirilmiş ve elde edilen yüzeylerin yüzey kalitesi ortalama pürüzlülük göz önüne alınarak değerlendirilmiştir. Veriler incelendiğinde;

- Liflere dik yapılan ölçümlerde en düşük $R a$ değerleri 2 no'lu kesici tipinde, 16000 dev/dak devir sayısında, $1000 \mathrm{~mm} /$ dak ilerleme hızında ve 4 işleme katman sayısında elde edilmiştir.

- Liflere paralel yapılan ölçümlerde en düşük $R a$ değerleri 2 no'lu kesici tipinde, 12000 dev/dak'da, $2000 \mathrm{~mm} /$ dak ilerleme hızında ve 4 işleme katman sayısında elde edilmiştir.

- İşleme derinliği arttıkça yüzey pürüzlülüğünde artış gözlemlenmektedir. Yüzey kalitesinin önemli olduğu durumlarda derin kesişlerden kaçınılmalıdır. Bir derin kesiş yerine iki veya daha fazla sığ kesişin daha düzgün yüzey vereceği görülmektedir.

- Pürüzlülük değerlerinin minimum olarak elde edilmesi için elde edilen veriler değerlendirilerek optimum noktada işleme gerçekleştirilmelidir.

- Belirli sınırlar içerisinde devir sayısı arttıkça pürüzlülük değerlerinde düşme meydana gelmektedir. Yüzey kalitesi için en uygun devir sayısını tespit ederek o devir sayısında kesişi gerçekleştirmek hem yüzey kalitesini arttıracak hem de kesicinin daha uzun süre keskin kalmasını sağlayacaktır.

\section{Teşekkür}

$\mathrm{Bu}$ makale, Oruç ARAS isimli yazarın "CNC frezeleme operasyonlarında, farklı ahşap kesitlerinde işleme parametreleri ile yüzey pürüzlülügü arasındaki ilişkinin araştırılması" başlıklı yüksek lisans tezi baz alınarak hazırlanmıştır.

\section{Yazar Katkıları}

Oruç Aras: Deneylerin yapılması, verilerin elde edilmesi, verilerin analiz edilmesi, Sait Dündar Sofuoğlu: Çalışma konusunun belirlenmesi ve deney tasarımının yapılması, verilerin analiz edilmesi, makalenin yazılması.

\section{Kaynaklar}

Aras, O., (2019), CNC frezeleme operasyonlarında, farklı ahşap kesitlerinde işleme parametreleri ile yüzey pürüzlülüğü arasındaki ilişkinin araştırılması, Kütahya Dumlupınar Üniversitesi, Fen Bilimleri Enstitüsü Yüksek lisans tezi, Kütahya.

Aydın, İ., Çolakoğlu, G., 2003. Odun yüzeylerinde pürüzlülük ve pürüzlülük ölçüm yöntemleri. Kafkas Üniversitesi Artvin Orman Fakültesi Dergisi, 1-2, 92-102.

Aykaç, E. (2018), Bambu'da işleme parametrelerinin yüzey kalitesi üzerine etkisinin araştırılması, Kütahya Dumlupınar Üniversitesi, Fen Bilimleri Enstitüsü Yüksek Lisans Tezi, Kütahya. 
Aykac, E., Sofuoğlu, S.D., (2021), Investigation of the effect of machining parameters on surface quality in bamboo. Tehnicki Vjesnik-Technical Gazette, 28(2), 684-689. DOI: 10.17559/TV-20200102202928

Bal, B.C., (2018), CNC makinelerinin bazı ayarlarının parça işleme süresi ve lif levhanın yüzey pürüzlülüğü üzerine etkileri, Mobilya ve Ahşap Malzeme Araştırmaları Dergisi, 1 (1), 21-30. DOI:10.33725/mamad.427588

Bal, B.C., Akçakaya, E. (2018), The effects of step over, feed rate and finish depth on the surface roughness of fiberboard processed with CNC machine, Mobilya ve Ahşap Malzeme Araştırmaları Dergisi, 1 (2), 86-93, DOI: 10.33725/mamad.481278

Bozkurt, A.Y. (1992), Odun anatomisi, İstanbul Üniversitesi: 3652, 975-404-230-6, İstanbul.

Bozkurt, A.Y., Erdin, N., (1997), Ağaç teknolojisi, İstanbul Üniversitesi Yayın No: 3998, 975-404-592-5, İstanbul.

Bozkurt, A.Y., Erdin, N., (2000), Odun anatomisi, İstanbul Üniversitesi: 4263, 975-404-5925, İstanbul.

Davim, J. P., Clemente, V. C., Silva, S., (2009), Surface roughness aspects in milling MDF (Medium Density Fibreboard). International Journal of Advanced Manufacturing Technology, 40(1-2), 49-55. DOI:10.1007/s00170-007-1318-z

Efe, H., Gürleyen, L., (2003), Bazı ağaç malzemelerde kesiş yönü, kesici adeti ve devir sayısının yüzey düzgünlüğüne etkileri, Gazi Üniversitesi Endüstriyel Sanatlar Ĕ̈itim Fakültesi Dergisi, 11(12), 34-44.

Hazir, E., Erdinler, E.S., Koc, K.H., (2018), Optimization of CNC cutting parameters using design of experiment (DOE) and desirability function. Journal of forestry research,29(5), 1423-1434. DOI:10.1007/s11676-017-0555-8

İşleyen, Ü.K., Karamanoğlu, M. (2019), The influence of machining parameters on surface roughness of MDF in milling operation, BioResources, 14(2), 3266-3277.

Jakub, S., Martıno, N., (2005), Wood surface roughness-What is it, Rosenheim Workshop, September, Boku University of Natural Resources and Applied Life Sciences, Vienna, Austria.

Kaçal, A., Sofuoğlu, S.D., (2013), Experimentally and Statistically Evaluating of Drilling of Massive Wooden Table which is Made of Scotch Pine (Pinus sylvestris L.), 21st International Wood Machining Seminar, Tsukuba International Congress Center, Tsukuba, Japan. August 4-7, 2013, 421-428.

Karagöz, Ü., (2010), Ahşap malzemenin CNC ile işlenmesinde yüzey kalitesini etkileyen işleme parametrelerinin belirlenmesi, Süleyman Demirel Üniversitesi, Fen Bilimleri Enstitüsü, Yüksek lisans tezi, Isparta.

Karagöz, Ü., (2011), CNC ile işlemede ahşap malzemenin yüzey kalitesini etkileyen faktörler, Kastamonu Üniversitesi, Orman Fakültesi Dergisi, 11 (1), 18-26

Koc, K.H., Erdinler, E.S., Hazır, E., Öztürk, E., (2017), Effect of CNC application parameters on wooden surface quality, Measurement, 107, 12-18.

Koç, K.H, Koç, R., (2005), Bilgisayar destekli üretim ve Türkiye mobilya endüstrisinin geleceği, Mobilya Dekorasyon, 67, 22-38. 
Malkoçoglu, A., Özdemir, T., (2006), The machining properties of some hardwoods and softwoods naturally grown in Eastern Black Sea Region of Turkey. Journal of Materials Processing Technology, 173(3), 315-320, DOI:10.1016/j.jmatprotec.2005.09.031

Marian, J.E., Suchland, O., (1962), Surface texture measurement theories, methods, applications, Forest Product Journal, 13, 303.

Sofuoğlu, S.D., (2008), Bazı yerli ağaç türü odunlarının işlenme özelliklerinden yüzey kalitesi üzerine etkileri, İstanbul Üniversitesi, Fen Bilimleri Enstitüsü, Doktora tezi, İstanbul.

Sofuoğlu, S.D., (2015a), Determination of optimal machining parameters of massive wooden edge-glued panels made of European larch (Larix decidua Mill.) using Taguchi design method, BioResources, 10(4), 6797-6808. DOI:10.15376/biores. 10.4.7772-7781

Sofuoğlu, S.D., (2016), Determination of optimal machining parameters of massive wooden edge- glued panels which is made of Scots Pine (Pinus sylvestris L.), using taguchi design methods, European Journal of Wood and Wood Products, 75 (1), 33-42.

Sofuoğlu, S.D., (2015b), Using artificial neural networks to model the surface roughness of massive wooden edge-glued panels made of scotch pine (Pinus sylvestris L.) in a machining process with computer numerical control, BioResources, 10(4), 6797-6808. DOI:10.15376/biores. 10.4.6797-6808

Sofuoğlu, S.D., Kaçal, A., (2013), Investigating of Machining Performance in Terms of Tool Wear and Hole Accuracy in Drilling of Particleboard Surfaced with Synthetic Resin Sheet, 21st International Wood Machining Seminar, Tsukuba International Congress Center, Tsukuba, Japan, August 4-7, 2013, s. 233-240.

Sofuoğlu, S.D., Kurtoğlu, A., (2014), Some machining properties of 4 wood species grown in Turkey, Turk J Agric For, 38(3) DOI:10.3906/tar-1304-124.

Stumbo, D.A., (1961), Surface texture measurements for quality and production control, Forest Products Journal, 10 -12, 122-124.

Sütçü, A., Karagöz, Ü., (2012), Effect of machining parameters on surface quality after face milling of MDF, Wood Research, 57 (2), 231-240.

Tiryaki, S., (2014), Odunun işlenmesinde yüzey pürüzlülüğ̈̈ üzerine etkili faktörler, SDÜ Orman Fakültesi Dergisi, 15, 176-182.

Tiryaki, S., Malkoçoğlu, A., Özşahin, Ş., (2014), Using artificial neural networks for modeling surface roughness of wood in machining process. Construction and Building Materials, 66, 329-335.

Tosun, M., (2021), Termo-mekanik yoğunlaştırmanın masif ağaç malzemenin işlenme özellikleri üzerine etkisi, Kütahya Dumlupınar Üniversitesi, Lisansüstü Eğitim Enstitüsü, Yüksek lisans tezi, Kütahya

TS 6956 EN ISO 4287, (2004), Geometrik mamul özellikleri (GMÖ)-Yüzey yapısı: Profil metodu terimler, tarifler ve yüzey yapısı parametreleri, Türk Standartları Enstitüsü, Ankara.

Usta, İ., Demirci, S., Kılıç, Y., (2007), Comparison of surface roughness of Locust Acacia (Robinia pseudoacacia L.) and European Oak (Quercus petraea (Mattu.) Lieble.) in terms of the preparative process by planning, Building and Environment, 42, 29882992. 